\title{
Polymer/Amorphous Salt Solid Dispersions of Ciprofloxacin
}

Hanah Mesallati ${ }^{\dagger}$ and Lidia Tajber ${ }^{\dagger}, *$

Suggested running head: Ciprofloxacin Amorphous Salt Solid Dispersions

\footnotetext{
${ }^{\dagger}$ Synthesis and Solid State Pharmaceutical Centre, School of Pharmacy and Pharmaceutical

Sciences, Trinity College Dublin, College Green, Dublin 2, Ireland.

*Corresponding author. Tel: +35318962787. Email: 1tajber@tcd.ie.
} 


\begin{abstract}
Purpose

To improve the pharmaceutical properties of amorphous ciprofloxacin (CIP) succinate salts via formulation as polymer/amorphous salt solid dispersions (ASSDs).
\end{abstract}

\title{
Methods
}

ASSDs consisting of an amorphous CIP/succinic acid 1:1 or 2:1 salt dispersed in PVP or Soluplus were produced by spray drying and ball milling. The solid state characteristics, miscibility, stability, solubility and passive transmembrane permeability of the ASSDs were then examined.

\section{Results}

The ASSDs had higher glass transition and crystallization temperatures than the corresponding amorphous succinate salts, and were also more stable during long-term stability studies. The results of inverse gas chromatography and thermal analysis indicated that the salts and polymers form a miscible mixture. The solubility of the pure drug in water and biorelevant media was significantly increased by all of the formulations. The permeability of the ASSDs did not differ significantly from that of the amorphous CIP succinate salts, however all samples were less permeable than the pure crystalline drug.

\section{Conclusions}


The formulation of amorphous CIP succinate salts as ASSDs with polymer improved their longterm stability, but did not significantly affect their solubility or permeability.

\title{
Keywords
}

Ciprofloxacin, amorphous salt solid dispersion, stability, solubility, permeability.

\author{
Abbreviations \\ ASD Amorphous solid dispersion \\ ASSD Amorphous salt solid dispersion \\ BM Ball milled \\ CIP Ciprofloxacin \\ CS 1:1 Ciprofloxacin hemisuccinate (ciprofloxacin/succinic acid 1:1) \\ CS 2:1 Ciprofloxacin succinate (ciprofloxacin/succinic acid 2:1) \\ G-T Gordon-Taylor \\ SD Spray dried \\ PAMPA Parallel artificial membrane permeability assay \\ PM Physical mixture
}




\section{Introduction}

Poor aqueous solubility is a commonly encountered problem when developing a new drug. A number of methods are used to increase the solubility of drugs, including the formation of salts and co-crystals, particle size reduction, cyclodextrin complexation, self-emulsification and amorphization (1). However, some methods are more suitable for particular drugs than others, depending on their chemical structure.

Ciprofloxacin (CIP) is a fluoroquinolone drug which possesses poor solubility and permeability. In the solid state CIP exists in the zwitterionic form, with a positively charged piperazine group and negatively charged carboxylate group. These oppositely charged groups interact to form chains of molecules, resulting in a strong crystal lattice. CIP therefore exhibits solid-state limited solubility (2). CIP also largely exists in the zwitterionic form in neutral media, with an overall neutral charge, which contributes to its low solubility. The solubility of CIP in water has been reported as 0.06 and $0.08 \mathrm{mg} / \mathrm{ml}$ at $25^{\circ} \mathrm{C}$ and $37{ }^{\circ} \mathrm{C}$, respectively (3). CIP is also poorly soluble in other common solvents such as ethanol, methanol, propanol, acetone and chloroform (4). The solubility of solid-state limited drugs such as CIP may be improved by disrupting the crystal lattice, which can be brought about via amorphization or salt formation, or a combination of both approaches (5).

In contrast to the crystalline state, amorphous solids consist of randomly arranged molecules, which lack long range order and possess more energy (6). Due to their disrupted crystal lattice, the crystal packing energy of amorphous solids is reduced, resulting in higher solubility (7). However, due to their excess free energy, amorphous materials generally have poor stability and tend to crystallize quickly (6). For this reason, they are often formulated as amorphous solid dispersions (ASDs). An ASD may be defined as a miscible mixture of at least two chemical 
components that form a single amorphous phase (8). Intramolecular interactions between the ASD constituents, such as hydrogen bonding and acid-base interactions, help to improve the stability of such systems, as they reduce the mobility of the molecules and increase the energy barrier to crystallization (9).

Salt formation is another method of improving the solubility of ionizable drugs. In this case an intermolecular interaction is formed between ionized groups in the drug and oppositely charged groups in the counterion. Removal of the dipole in zwitterions such as CIP via salt formation will often result in improved solubility, due to a decrease in crystal lattice energy (10). Salts may also increase the solubility of drugs by altering the $\mathrm{pH}$ as they dissolve. The formation of crystalline CIP salts with numerous acidic counterions has been described, all of which significantly increased the solubility of the drug $(3,11)$. By combining the solubility benefits of amorphization with those of salt formation, the preparation of amorphous salts would be expected to increase the solubility of a drug more than either approach alone. However, there is also a risk that such formulations would crystallize during storage or dissolution, and thus negate their solubility advantage. Paluch et al prepared amorphous CIP/succinic acid salts with a 1:1 (CS 1:1) and 2:1 (CS 2:1) molar ratio. These amorphous salts increased the solubility of CIP in water by over 300 times, and were also more soluble than the equivalent crystalline salts. However, both salts crystallized during solubility and water sorption studies (3).

In contrast to CIP salts, little research has focused on ASDs of CIP. Our group recently described the production of CIP ASDs by ball milling, consisting of the drug and 40-60\% (w/w) polymer (12). It was discovered that fully X-ray amorphous ASDs could only be obtained with acidic polymers. In each case an ionic interaction was formed between the protonated secondary amine of CIP and the negatively charged carboxylate of the polymers. A similar interaction is also 
present in CIP salts $(3,11)$. These ASDs were found to significantly improve the solubility of CIP in water and biorelevant media, without decreasing the permeability or antimicrobial activity of the drug (12).

Following the promising results obtained with the CIP ASDs and amorphous CS 1:1 and CS 2:1 salts, the primary aim of this project was to determine whether a combination of these approaches could improve the stability and solubility of these salts. Amorphous salt solid dispersions (ASSDs) of CIP, consisting of the CS 1:1 or CS 2:1 salt dispersed in 20-60\% (w/w) PVP or Soluplus, were produced by spray drying and ball milling. These polymers are amorphous, with the latter often used to form solid dispersions by hot melt extrusion (13). Such polymers have been shown to increase the stability of ASDs by reducing the molecular mobility of the components and increasing the energy barrier for crystallization (14). While many published studies have independently shown the benefits of drug/polymer ASDs and amorphous salts, literature concerning polymer/amorphous salt solid dispersions is scarce, making the samples produced in this study relatively unique. However, Patel et al used a similar approach to improve the physical properties of the amorphous tenoxicam/arginine 1:2 salt. The authors found that the formulation of spray dried ASSDs with 10-50\% (w/w) PVP resulted in much higher $\mathrm{T}_{\mathrm{g}}$ 's than the pure 1:2 amorphous salt, and also helped to maintain supersaturation of the drug during solubility studies (15).

Of particular interest in this study was the interaction and miscibility of the CIP succinate salts with PVP and Soluplus, as an ASD will have greater stability if its components interact specifically with one another and are mixed on a molecular level. Fourier transform infrared spectroscopy (FTIR) was used to investigate the intermolecular interactions present in the ASSDs, and their miscibility was examined by differential scanning calorimetry (DSC) and 
inverse gas chromatography (IGC). In addition, the stability, solubility and permeability of the amorphous CS 1:1 and CS 2:1 salts and ASSDs were examined. Finally, a comprehensive comparison of the physicochemical and pharmaceutical properties of the amorphous salts and ASSDs, as well as the CIP/acidic polymer ASDs that were previously produced (12), is provided in order to highlight the relative advantages and disadvantages of these formulation approaches for CIP.

\section{Materials and Methods}

\section{Materials}

Ciprofloxacin (CIP) was obtained from Carbosynth Limited, Berkshire, UK. Succinic acid (Aldrich, Milwaukee, USA) was used to form amorphous succinate salts with CIP. The PXRD diffractograms and DSC thermograms of these starting material powders are shown in Figure S1. Polyvinylpyrrolidone K17 (PVP: Plasdone ${ }^{\circledR}$ C-15, ISP Technologies, New Jersey, USA; average molecular weight 10,000) and polyvinyl caprolactam-polyvinyl acetate-polyethylene glycol graft copolymer (Soluplus ${ }^{\circledR}$, BASF SE, Ludwigshafen, Germany) were used to form ASSDs with these salts. Fasted state simulated gastric fluid was produced by adding $60 \mathrm{mg}$ SIF ${ }^{\circledR}$ Powder Original (biorelevant.com, Surrey, United Kingdom) to one liter of FaSSGF HCl solution, consisting of $34 \mathrm{mM} \mathrm{NaCl}$ adjusted to $\mathrm{pH} 1.6$ with $\mathrm{HCl}$. Fasted state simulated intestinal fluid (FaSSIF) was produced by adding $2.24 \mathrm{~g} \mathrm{SIF}^{\circledR}$ Powder Original to one liter of FaSSIF phosphate buffer, consisting of $19.5 \mathrm{mM} \mathrm{NaOH}, 25 \mathrm{mM} \mathrm{NaH}_{2} \mathrm{PO}_{4} \cdot \mathrm{H}_{2} \mathrm{O}$ and $106 \mathrm{mM} \mathrm{NaCl}$, adjusted to $\mathrm{pH}$ 6.5 with $\mathrm{NaOH}$. NaOH pellets were obtained from Riedel-de Haën ${ }^{\circledR}$, Seelze, Germany, $\mathrm{NaH}_{2} \mathrm{PO}_{4} . \mathrm{H}_{2} \mathrm{O}$ from Merck, Darmstadt, Germany and $\mathrm{NaCl}$ from Sigma-Aldrich Ireland Ltd., 
Arklow, Ireland. Triethylamine, dodecane, lecithin (L- $\alpha$-phosphatidylcholine, Type XVI-E) and phosphate buffered saline (PBS) tablets were obtained from Sigma-Aldrich Ireland Ltd., Arklow, Ireland. All other chemicals and solvents were of analytical grade.

\section{Methods}

\section{Ball Milling}

For each ASSD, milling was performed at room temperature $\left(22-25^{\circ} \mathrm{C}\right)$ using a Retsch ${ }^{\circledR}$ planetary ball mill PM 100 (Haan, Germany). $2.5 \mathrm{~g}$ of powder was added to $50 \mathrm{ml}$ stainless steel grinding bowls. Three stainless steel milling balls of $20 \mathrm{~mm}$ diameter and $32 \mathrm{~g}$ weight were used. Amorphous ciprofloxacin hemisuccinate (CS 1:1) and ciprofloxacin succinate (CS 2:1) salts were produced by dry ball milling CIP and succinic acid in a 1:1 and 2:1 molar ratio, respectively, for a total of 6 hours. ASSDs were produced by adding 40\% (w/w) PVP or Soluplus to these salts, and milling for a further $60 \mathrm{~min}$. Milling was carried out in intervals of $15 \mathrm{~min}$ with 10 min breaks in between.

\section{Spray Drying}

ASSDs were produced using a Büchi B-290 mini spray dryer (Flawil, Switzerland) with a 1.5 $\mathrm{mm}$ cap and $0.7 \mathrm{~mm}$ tip. The pump speed was $30 \%(9-10 \mathrm{ml} / \mathrm{min})$. The aspirator was set to $100 \%$. A mixture of nitrogen (with a pressure of 6 bar) and air was used as the drying gas. $2 \%$ (w/v) solutions of a 1:1 molar ratio of CIP and succinic acid, plus 20-60\% (w/w) PVP were prepared in water. This was also repeated using $40 \%$ (w/w) Soluplus. The solutions were then spray dried with an inlet temperature of $150^{\circ} \mathrm{C}$.

\section{Powder X-ray Diffraction (PXRD)}


PXRD was carried out at room temperature using a benchtop Rigaku MiniflexII X-ray diffractometer (Tokyo, Japan) and a Haskris cooler (Illinois, USA). The samples were scanned from 5 to $40^{\circ} 2 \theta$ degrees with a step width of 0.05 , scan rate of $0.05^{\circ}$ per second and signal collection time of $1 \mathrm{sec}$ per step. The output voltage and current of the tube $(\mathrm{Cu}, 1 \mathrm{~kW}$ normal focus) were $30 \mathrm{kV}$ and $15 \mathrm{~mA}$, respectively.

\section{Solid-State Fourier Transform Infrared Spectroscopy (FTIR)}

FTIR was performed using a Spectrum One FT-IR Spectrometer (Perkin Elmer, Connecticut, USA) equipped with Spectrum Software version 6.1. A spectral range of $450-4000 \mathrm{~cm}^{-1}$,

resolution of $4 \mathrm{~cm}^{-1}$, scan number of 10 and scan speed of $0.2 \mathrm{~cm} / \mathrm{sec}$ were used. $\mathrm{KBr}$ disks were produced by direct compression, using a pressure of approximately 10 bar for $1 \mathrm{~min}$. A sample loading of $1 \%(\mathrm{w} / \mathrm{w})$ was used.

\section{Differential Scanning Calorimetry (DSC)}

DSC was carried out with a Mettler Toledo DSC (Schwerzenbach, Switzerland). The purge gas was nitrogen. Approximately 5-10 mg samples were analyzed in sealed $40 \mu \mathrm{l}$ aluminum pans with pierced lids. In order to elucidate the glass transition temperature $\left(\mathrm{T}_{\mathrm{g}}\right)$ of the ASSDs, the samples were first heated from 25 to $70-100{ }^{\circ} \mathrm{C}$ to remove water present in the powder. When cool, the samples were reheated from 25 to $300{ }^{\circ} \mathrm{C}$ at a rate of $10{ }^{\circ} \mathrm{C} / \mathrm{min}$. All measurements were carried out in triplicate. The thermograms were analyzed using Mettler Toledo STARe software (version 6.10). The midpoint of the transition was taken as the $\mathrm{T}_{\mathrm{g}}$.

\section{Thermogravimetric Analysis (TGA)}


TGA was carried out with a Mettler TG50 measuring module coupled to a Mettler Toledo MT5 balance (Schwerzenbach, Switzerland). Approximately 8-10 mg samples were analyzed in open aluminum pans, using nitrogen as the purge gas. Samples were heated from 25 to $300{ }^{\circ} \mathrm{C}$ at a rate of $10^{\circ} \mathrm{C} / \mathrm{min}$. Mettler Toledo STARe software (version 6.10) was used to analyze the thermograms obtained.

\section{Determination of Solubility Parameters Using Inverse Gas Chromatography (IGC)}

IGC was carried out on the CS 1:1 and CS 2:1 amorphous salts using a Surface Measurement Systems (SMS) iGC 2000 (London, UK) equipped with a flame ionization detector (FID). Samples were sieved through a $180 \mu \mathrm{m}$ mesh and packed into a glass column. The carrier gas used was helium, with a flow rate of $5 \mathrm{ml} / \mathrm{min}$. The column was held at a temperature of $30{ }^{\circ} \mathrm{C}$ (303 K). Methane was used as a non-interacting internal standard for dead time correction. Nine different solvents were used in this study. These were classified according to the type of interactions they can form with the stationary phase. Nonane, octane and heptane (the n-alkanes) may form dispersion interactions; acetone, dichloromethane, chloroform and ethyl acetate form polar bonds; and ethanol and 2-propanol participate in hydrogen bonding. The retention time of each solvent was determined by measuring the peak maximum. The solubility parameters of the salts were calculated using the method described by Kitak et al (16):

$\chi_{1,2}^{\infty}=\ln \left(\frac{273.15 \mathrm{R}}{\mathrm{P}_{1}^{0} \mathrm{~V}_{\mathrm{g}} \mathrm{M}_{\mathrm{r}, 1}}\right)-\frac{\mathrm{P}_{1}^{0}}{\mathrm{RT}}\left(\mathrm{B}_{11}-\mathrm{V}_{1}\right)+\ln \left(\frac{\rho_{1}}{\rho_{2}}\right)-\left(1-\frac{\mathrm{V}_{1}}{\mathrm{~V}_{2}}\right)$

$\chi_{1,2}^{\infty}$ is the interaction parameter, $\mathrm{R}$ is the gas constant, $\mathrm{T}$ is the temperature, $\mathrm{P}_{1}^{0}$ is the saturated vapor pressure of the solvent, $\mathrm{V}_{\mathrm{g}}$ is the specific retention volume, $\mathrm{M}_{\mathrm{r}, 1}$ is the molecular mass of the solvent, $B_{11}$ is the second virial coefficient, $V_{1}$ and $V_{2}$ are the molar volumes of the solvent 
and solute respectively, and $\rho_{1}$ and $\rho_{2}$ are their respective densities. The molar volumes of CS 1:1 and CS 2:1 were estimated by dividing their molecular weight by their density.

$\chi_{1,2}^{\infty}$ is linearly correlated to $\delta_{1 \mathrm{i}}$ as follows (16):

$\frac{\delta_{1 i}^{2}}{R T}-\frac{\chi_{(1,2) \mathrm{i}}^{\infty}}{V_{1}}=\frac{2 \delta_{2}}{R T} \delta_{1 i}-\left(\frac{\delta_{2}^{2}}{R T}+\frac{\chi_{\mathrm{s}}^{\infty}}{V_{1}}\right)$

$\delta_{2}$ is the solubility parameter of the solute, which can be found from the intersection of the straight line with the y-axis (equal to the term in brackets in Eq. 2).

Following IGC analysis CS 1:1 and CS 2:1 were analyzed by PXRD.

\section{Dynamic Vapor Sorption (DVS)}

Moisture sorption and desorption analysis was carried out using a DVS Advantage 1 automated vapor gravimetric sorption analyzer (Surface Measurement Systems, London, UK). The temperature was maintained at $25.0 \pm 0.1^{\circ} \mathrm{C}$. Approximately $10 \mathrm{mg}$ samples of ASSD were added to the sample basket and placed in the instrument. These were equilibrated at $0 \%$ relative humidity (RH) until a constant mass was obtained ( $\mathrm{dm} / \mathrm{dt} \leq 0.002 \mathrm{mg} / \mathrm{min})$. The reference mass was recorded and sorption-desorption analysis was then carried out between 0 and $90 \% \mathrm{RH}$, in steps of $10 \% \mathrm{RH}$. At each stage, the sample mass was equilibrated (dm/dt $\leq 0.002 \mathrm{mg} / \mathrm{min}$ for at least $10 \mathrm{~min}$ ) before moving to the next RH level. An isotherm was calculated from the complete sorption and desorption profile. PXRD was carried out on all of the samples following the analysis.

\section{Stability Study}


The ASSDs and amorphous CS 1:1 and CS 2:1 salts were stored at room temperature $\left(22-25^{\circ} \mathrm{C}\right)$ under dry storage conditions in a desiccator (silica gel). Samples of each powder were taken at regular intervals for a period of 12 months. PXRD was used to determine whether crystallization had occurred in any of the samples.

\section{Dynamic Solubility Studies}

10-20 $\mathrm{ml}$ of water, FaSSIF or FaSSGF were added to $40 \mathrm{ml}$ glass vials. They were placed into jacketed beakers connected to a Lauda M12 waterbath (Lauda-Königshofen, Germany) and allowed to equilibrate to $37^{\circ} \mathrm{C}$. A quantity of sample in excess of the expected saturated solubility (100-700 mg) was added to the vials, which were stirred at $1000 \mathrm{rpm}$. Samples were drawn from the vial at specific time points over a 2 hour period. The aliquots were filtered with $0.45 \mu \mathrm{m}$ PTFE membrane filters (VWR, USA). The filtered solutions were then diluted with a $2.45 \mathrm{~g} / \mathrm{l}$ solution of phosphoric acid, previously adjusted to $\mathrm{pH} 3.0$ with triethylamine. The concentration of CIP in each of the diluted samples was measured by UV spectrophotometry. The solubility studies were repeated at least in triplicate with each medium. The $\mathrm{pH}$ of the solutions was measured before the addition of the samples and at the end of the 2 hour study using a Thermo Orion 420A + pH meter (Thermo Scientific, Hampshire, UK). The solid material left in the vials at the end of the studies was filtered and analyzed by PXRD.

\section{UV Spectrophotometry}

UV analysis was carried out using a Shimadzu UV-1700 PharmaSpec UV-vis spectrophotometer (Shimadzu Corp., Kyoto, Japan). Quartz cells with a $1 \mathrm{~cm}$ optical path length were used for all measurements. The instrument was first blanked using a $2.45 \mathrm{~g} / \mathrm{l}$ solution of phosphoric acid, previously adjusted to $\mathrm{pH} 3.0$ with triethylamine. UV absorbance was measured at $278 \mathrm{~nm}$. A 
range of concentrations of CIP was also prepared using this buffer in order to construct a calibration curve.

\section{Parallel Artificial Membrane Permeability Assay (PAMPA)}

Permeability studies were carried out using the lipid-PAMPA method described previously $(12,17)$. A 96-well MultiScreen Filter Plate, with underdrain removed, was used as the donor plate, and a 96-well MultiScreen Transport Receiver Plate as the acceptor plate (Millipore Corporation, Billerica, MA, USA). Samples were dissolved in $\mathrm{pH} 7.4 \mathrm{PBS}$, at a concentration equivalent to $180 \mu \mathrm{M}$ CIP. $300 \mu \mathrm{l}$ of PBS pH 7.4 was added to each well of the acceptor plate. 5 $\mu 1$ of a $1 \%(\mathrm{w} / \mathrm{v})$ solution of lecithin in dodecane was added to the filter within each donor well to form an artificial membrane. $150 \mu \mathrm{l}$ of the drug solutions were immediately added to each well of the donor plate in triplicate. The donor plate was then placed into the acceptor plate and incubated at room temperature for 16 hours. Following incubation, the contents of each well in the acceptor plate was diluted 1:4 with HPLC mobile phase and filtered with $0.45 \mu \mathrm{m}$ PTFE membrane filters (VWR, USA). The concentration of CIP in each sample was then measured using HPLC.

The effective permeability $\left(\mathrm{P}_{\mathrm{e}}\right)$ of the samples was calculated using the following equation (18):

$P_{e}=-\ln (1-r)\left(\frac{V_{D} V_{A}}{\left(V_{D}+V_{A}\right) A t}\right)$

where $\mathrm{r}=\frac{[\text { Drug }]_{\text {Acceptor }}}{[\text { Drug }]_{\text {Equilibrium }}}$

$\mathrm{V}_{\mathrm{D}}$ and $\mathrm{V}_{\mathrm{A}}$ are the volumes of the donor and acceptor compartment, respectively, in $\mathrm{cm}^{3}, \mathrm{t}$ is the incubation time in seconds, and $\mathrm{A}$ is the active surface area of the membrane (equal to the 
membrane area multiplied by the porosity ratio. For Millipore MultiScreen Permeability Filter Plate membranes this is equal to $0.24 \mathrm{~cm}^{2} \times 100 \%$, or $0.24 \mathrm{~cm}^{2}$ ) (17). [Drug] Acceptor is the concentration of the drug in the acceptor compartment at the end of the assay. [Drug]Equilibrium is determined by measuring the concentration of a reference solution, containing the drug at the theoretical equilibrium concentration (the overall concentration of the donor and acceptor solutions combined). Given that the acceptor and donor compartments used in this study had a volume of $300 \mu \mathrm{l}$ and $150 \mu \mathrm{l}$ respectively, the equilibrium concentration of the drug should theoretically be one-third of that of the original solution added to the donor well.

\section{High-Performance Liquid Chromatography (HPLC)}

HPLC was carried out at room temperature with a Shimadzu ${ }^{\circledR}$ 10Avp HPLC system and SPD10Avp UV-vis detector (Kyoto, Japan) at $278 \mathrm{~nm}$. A Luna 5u C8 column, with a length of 250 $\mathrm{mm}$, internal diameter of $4.6 \mathrm{~mm}$ and $5 \mu \mathrm{m}$ particle size was used. The mobile phase consisted of 13 volumes of acetonitrile and 87 volumes of a $2.45 \mathrm{~g} / \mathrm{l}$ solution of phosphoric acid, previously adjusted to $\mathrm{pH} 3.0$ with triethylamine. An injection volume of $10 \mu \mathrm{l}$ and flow rate of $1.5 \mathrm{ml} / \mathrm{min}$ for 15 min was used.

\section{Statistical Analysis}

Statistical analysis was carried out using Minitab ${ }^{\circledR} 16$ software. Two-sample Student $t$ tests and one-way analysis of variance (ANOVA) with Tukey's multiple comparison test were used to compare results. A $p$-value of $\leq 0.05$ was considered significant.

\section{Results and Discussion}




\section{Production of Amorphous Salt Solid Dispersions}

Amorphous CS 1:1 and CS 2:1 were previously produced by Paluch et al via spray drying and ball milling, respectively (3), whereas in this study ball milling was used to prepare both amorphous salts. Six hours of high intensity milling $(600 \mathrm{rpm})$ was required to obtain fully X-ray amorphous powders. PVP was chosen as the primary polymer to include in the CIP/succinic acid ASSDs as it is hydrophilic and amorphous, and is commonly used to produce ASDs of poorly soluble drugs (19). However, when a 1:1 molar ratio of CIP and succinic acid, plus 20-60\% (w/w) PVP, were ball milled (BM) together for 4 hours, a partially crystalline product was obtained, with PXRD peaks primarily matching those of CIP, along with one small peak of the CS 1:1 salt at approximately $5.52 \theta$ degrees (Figure S2). The sample containing 20\% (w/w) PVP possessed the lowest degree of crystallinity following milling, as detected by PXRD, whereas more crystalline products were obtained when the proportion of PVP was increased to 40 or $60 \%$ $(\mathrm{w} / \mathrm{w})$. The polymer therefore appears to have hindered the formation and amorphization of the salt, although the degree of crystallinity (by PXRD) of the components did decrease over time during milling. It was recently shown that binary ASDs of CIP could not be formed with neutral polymers, such as PVP and Soluplus, as the interactions between the drug and excipient were too weak to yield a fully amorphous solid dispersion. In contrast, ball milling with acidic polymers such as Eudragit L100, Carbopol and HPMCAS resulted in fully amorphous samples, thanks to stabilizing ionic interactions between the positively charged amino group of the drug and negatively charged carboxylate of the polymer (12).

As initial milling of all three individual starting materials was unsuccessful, CIP and succinic acid were then pre-milled, in order to form the amorphous CS 1:1 or 2:1 salt. These salts were subsequently milled with 40\% (w/w) PVP for a further 60 min (BM CS 1:1/40\% PVP and BM 
CS 2:1/40\% PVP). The CS 1:1 salt was also milled with Soluplus for 60 min (BM CS 1:1/40\% Soluplus). Like PVP, this polymer is amorphous, and has been used successfully to form ASDs of other poorly soluble drugs by ball milling (20). As can be seen in Figure 1, the use of premilling resulted in an X-ray amorphous product for each of these systems.

Spray drying was also used to produce ASSDs containing CS 1:1. The required amount of succinic acid was first dissolved in warm water, followed by CIP, and then various quantities of PVP. Due to the poor solubility of CIP, solutions of CS 2:1 could not be prepared, and thus milling was the only suitable method of production for this salt. CS 1:1 with 20-60\% (w/w) PVP resulted in fully X-ray amorphous ASSDs (labelled as SD CS 1:1/20\% PVP, 40\% PVP and 60\% PVP, Figure 1). However, when a solution of CS $1: 1$ with $40 \%$ (w/w) Soluplus was spray dried (SD), a partially crystalline product was obtained, as shown by PXRD and DSC (Figure S3). The PXRD diffractogram of this sample contained a number of peaks corresponding to the CS 1:1 salt, as well as the most intense peak of CIP and succinic acid at approximately 25-26 $2 \theta$ degrees. Therefore, the process used to form the ASSDs, as well as the type and proportion of polymer, affects the solid state of the product.

\section{Solid-State Fourier Transform Infrared Spectroscopy (FTIR)}

The FTIR spectra of the ASSDs, CS 1:1, CS 2:1 and the starting materials are shown in Figure 2. In the spectrum of crystalline CIP, two peaks are present at 1590 and $1375 \mathrm{~cm}^{-1}$. These correspond to the $\mathrm{C}=\mathrm{O}$ asymmetric and symmetric vibrations, respectively, of the carboxylate ion (21). These peaks are absent from the spectra of the ASSDs. Instead, a peak can be seen at 1721-1727 $\mathrm{cm}^{-1}$, due to the $\mathrm{C}=\mathrm{O}$ stretch of the $\mathrm{COOH}$ of CIP. The FTIR spectrum of the 
unionized form of CIP was also found to have a peak at $1724 \mathrm{~cm}^{-1}$ (2). Therefore, the carboxylic acid of CIP is protonated in these ASSDs, which was also found to be the case for the CS 1:1 and CS 2:1 salts (3). The broad peak at $2400-2600 \mathrm{~cm}^{-1}$ in the spectrum of CIP can be assigned to the stretching vibrations of the $\mathrm{NH}_{2}{ }^{+}$group (22). An enlarged section of the spectrum, showing the $\mathrm{NH}_{2}{ }^{+}$peak of the drug, is shown in Figure 2.I. Similar bands have been identified in the FTIR spectra of the CS 1:1 and CS 2:1 salts. This positively charged group was found to form an ionic bond with the carboxylate groups of succinic acid (3). A low intensity band can be found at approximately $2490 \mathrm{~cm}^{-1}$ in the spectra of each of the ASSDs, indicating that the piperazine secondary amine of CIP is also protonated in these samples.

The peak at approximately $1618 \mathrm{~cm}^{-1}$ in the spectrum of crystalline CIP can be assigned to the $\mathrm{C}=\mathrm{O}$ stretch of the ketone carbonyl (21). This band appears at $1627-1629 \mathrm{~cm}^{-1}$ in the spectra of CS 1:1, CS 2:1 and the ASSDs. This shift was also seen in the FTIR spectra of binary CIP ASDs formed with acidic polymers, and was attributed to the changes in hydrogen bonding that occur when the carboxylic acid of CIP becomes protonated (12). When the COOH group of CIP is unionized, it forms an intramolecular hydrogen bond with the neighboring ketone group (2). This bond was also found in the crystalline CS 1:1 and CS 2:1 salts (3), and appears to be present in these ASSDs as well.

The spectrum of PVP shows a broad peak from about $1600-1750 \mathrm{~cm}^{-1}$, with a maximum at 1659 $\mathrm{cm}^{-1}$, due to the $\mathrm{C}=\mathrm{O}$ stretch of the pyrrolidone carbonyl group. This is the most likely functional group of PVP to participate in hydrogen bonding, and the formation of such interactions is usually associated with a shift in the corresponding peak to lower wavenumbers (8). Chen et al observed a peak at $1657 \mathrm{~cm}^{-1}$ in the FTIR spectrum of PVP, even after it was dried under vacuum at $40{ }^{\circ} \mathrm{C}$ for 24 hours, due to the participation of this group in hydrogen bonding with absorbed 
water. When the polymer was more thoroughly dried this peak shifted to $1667 \mathrm{~cm}^{-1}(23)$. The carbonyl stretch of PVP also shifted to $1663-1667 \mathrm{~cm}^{-1}$ in the spectra of the ASSDs (Figure 2.I), which may be due to a reduction in the hydrogen bonding of PVP's carbonyl group with water molecules in the ASSDs. Similarly, the carbonyl peak of the polymer was found to shift to higher wavenumbers in nimesulide/PVP ASDs, as the more hydrophobic environment of the ASD resulted in a decrease in PVP-water hydrogen bonds (14). The fact that the carbonyl peak of PVP did not shift to lower wavenumbers in the spectra of the ASSDs suggests that this polymer did not form hydrogen bonds with the CS 1:1 and 2:1 salts.

The peaks at $1637 \mathrm{~cm}^{-1}$ and $1741 \mathrm{~cm}^{-1}$ in the spectrum of Soluplus correspond to the $\mathrm{C}=\mathrm{O}$ stretch of the caprolactam carbonyl and ester carbonyl, respectively. These bands are overlapped with those of the ketone and $\mathrm{COOH}$ carbonyl stretches of CIP in BM CS 1:1/40\% Soluplus, with the combined peaks appearing at 1634 and $1721 \mathrm{~cm}^{-1}$, respectively (Figure 2.II). This makes it difficult to say with certainty whether the carbonyl peaks of Soluplus are shifted in this ASSD. However, as the caprolactam peaks of the ASSD and pure polymer differed by only $3 \mathrm{~cm}^{-1}$, this shift may simply be due to experimental error. Regarding the peak at $1721 \mathrm{~cm}^{-1}$ in the spectrum of the ASSD, a slight shoulder was visible at $\sim 1738 \mathrm{~cm}^{-1}$, which may be assigned to the ester carbonyl stretch of the polymer. Therefore, neither carbonyl peak of Soluplus underwent significant shifts upon ASSD formation. In addition, upon comparison of the FTIR spectra of the ASSD and a physical mixture, containing the CS 1:1 amorphous salt and Soluplus in the same ratio as in the ASSD, no significant differences were seen. Therefore, like PVP, no evidence of hydrogen bonding between CS 1:1 and Soluplus could be detected in this ASSD. 


\section{Thermal Analysis and Estimation of Component Miscibility}

DSC thermograms of the ASSDs are shown in Figure 3, and a summary of their thermal properties is given in Table I. Due to their high water content, the samples were first heated from 25 to $70-100{ }^{\circ} \mathrm{C}$ to enable water evaporation; however, upon reheating some residual water did appear to be present. The $\mathrm{T}_{\mathrm{g}}$ of $\mathrm{CS} 1: 1$ was detected at $86.7 \pm 0.5^{\circ} \mathrm{C}$, which is identical to the $\mathrm{T}_{\mathrm{g}}$ of pure amorphous CIP (2). The $\mathrm{T}_{\mathrm{g}}$ of CS $2: 1$ on the other hand was only $69.3 \pm 1.0^{\circ} \mathrm{C}$. A combination of factors may have resulted in the observed $\mathrm{T}_{\mathrm{g}}$ 's of these salts. On the one hand, the presence of ionic interactions between a drug and co-former in an amorphous formulation should reduce the molecular mobility of the system, resulting in a higher $\mathrm{T}_{\mathrm{g}}$. However, this may have been offset by the particularly low $\mathrm{T}_{\mathrm{g}}$ of succinic acid, which is believed to be less than 30 ${ }^{\circ} \mathrm{C}$ (24). The lower $\mathrm{T}_{\mathrm{g}}$ of CS 2:1 relative to CS 1:1 may be due to weaker interactions between the drug and acid when they are present at this ratio.

Table I. Thermal Properties of CIP Amorphous Salts and ASSDs

\begin{tabular}{|c|c|c|c|}
\hline Sample & $\mathbf{T}_{\mathrm{g}}\left({ }^{\circ} \mathrm{C}\right)$ & $\begin{array}{l}\text { Crystallization } \\
\text { onset }\left({ }^{\circ} \mathrm{C}\right)\end{array}$ & $\begin{array}{l}\text { Crystallization } \\
\text { peak }\left({ }^{\circ} \mathrm{C}\right)\end{array}$ \\
\hline CS 1:1 & $86.7 \pm 0.5$ & $105.3 \pm 1.2$ & $110.3 \pm 1.0$ \\
\hline CS 2:1 & $69.3 \pm 1.0$ & $\begin{array}{l}103.8 \pm 0.5 / \\
115.3 \pm 0.4\end{array}$ & $\begin{array}{l}107.6 \pm 0.2 / \\
121.8 \pm 0.1\end{array}$ \\
\hline BM CS $1: 1 / 40 \%$ PVP & $91.2 \pm 0.8$ & $129.1 \pm 0.2$ & $136.9 \pm 0.2$ \\
\hline BM CS $2: 1 / 40 \%$ PVP & $98.4 \pm 0.9$ & $125.2 \pm 0.8$ & $132.3 \pm 0.7$ \\
\hline $\begin{array}{l}\text { BM CS 1:1/40\% } \\
\text { Soluplus }\end{array}$ & $81.7 \pm 0.8$ & $112.6 \pm 0.4$ & $117.5 \pm 0.4$ \\
\hline SD CS $1: 1 / 20 \%$ PVP & $90.2 \pm 0.1$ & $111.3 \pm 1.2$ & $116.7 \pm 1.4$ \\
\hline SD CS $1: 1 / 40 \%$ PVP & $93.0 \pm 0.8$ & $130.6 \pm 0.0$ & $140.8 \pm 0.1$ \\
\hline
\end{tabular}




\begin{tabular}{|l|l|l|l|}
\hline SD CS 1:1/60\% PVP & $122.4 \pm 1.6$ & $145.0 \pm 0.3$ & $159.2 \pm 1.0$ \\
\hline
\end{tabular}

DSC is commonly used to determine whether the components of an ASD are miscible or not. A single $T_{g}$ was seen in the thermograms of all of the ASSDs. This suggests that the amorphous salts are miscible with PVP and Soluplus, and that phase separation does not occur in the ASSDs. In contrast, if the components of an ASD are partially or entirely immiscible, two $\mathrm{Tg}_{\mathrm{g}}$ 's should be seen upon DSC analysis (25). The Tg's of PVP K17 and Soluplus have been reported as 125.2 and $72{ }^{\circ} \mathrm{C}$, respectively $(20,26)$. If the two components of an ASD are miscible, its $\mathrm{T}_{\mathrm{g}}$ should be located in between the $\mathrm{T}_{\mathrm{g}}$ of the pure drug (or salt in this case) and the polymer (25), and this was found to be the case for all of the ASSDs. With the ASSDs containing PVP this resulted in an increase in $T_{g}$ relative to the relevant pure amorphous salt, whereas the $T_{g}$ of $B M$ CS $1: 1 / 40 \%$ Soluplus was approximately $5{ }^{\circ} \mathrm{C}$ lower than CS $1: 1$, due to the comparatively low $\mathrm{T}_{\mathrm{g}}$ of the polymer. An additional indication of miscibility in the spray dried samples is that as the proportion of PVP increased, so did the $\mathrm{T}_{\mathrm{g}}$.

Another common approach for determining the miscibility of the components in an ASD is to calculate their solubility parameters. The group contribution method may be used to find the solubility parameters of drugs and polymers, however it will not give accurate results for salts (16). The total solubility parameters $\left(\delta_{t}\right)$ of the amorphous CS 1:1 and CS 2:1 salts were therefore determined by IGC, while those of the polymers were obtained from literature. The $\delta_{\mathrm{t}}$ values were 19.9, 20.3, 22.7 and 19.4 $\mathrm{MPa}^{0.5}$ for CS 1:1, CS 2:1, PVP (16) and Soluplus (13), respectively. According to Greenhalgh et al, a difference of less than $7 \mathrm{MPa}^{0.5}$ between the solubility parameters of two components indicates that they are miscible, whereas if they differ by more than $10 \mathrm{MPa}^{0.5}$ they are expected to be immiscible (27). These results therefore confirm 
the miscibility of the amorphous salts and the polymers, with a $\delta_{\mathrm{t}}$ difference of $\leq 2.8 \mathrm{MPa}^{0.5}$ being obtained in each case.

The thermograms of all of the ASSDs contained exothermic peaks due to cold crystallization of their amorphous content. It is clear from Figure 3 that the CS 2:1 amorphous salt differs from the other samples by the presence of two exotherms in this region, peaking at $107.6{ }^{\circ} \mathrm{C}$ and $121.8^{\circ} \mathrm{C}$. PXRD analysis was carried out on the sample immediately following each crystallization event. Identical PXRD peaks were obtained in both cases, matching those of crystalline anhydrous CS 2:1 (3); however, they became more intense after the second crystallization event. Similar double exothermic peaks have been reported for a number of drugs following milling. Trasi et al attributed the first peak in the thermogram of milled griseofulvin to the surface crystallization of particles that had nuclei on their surfaces, while the second peak was due to crystallization of the bulk of these particles, as well as particles that were not nucleated (28). Therefore, the occurrence of two crystallization peaks in the thermogram of CS 2:1 indicates that the particles may have contained a number of surface crystal nuclei following milling, which were too small to be detected by PXRD.

All of the ASSDs crystallized at higher temperatures than the corresponding salt, which can be attributed to the presence of polymer. The long chains of polymers can delay crystallization by sterically hindering the diffusion of drug molecules and formation of a crystal lattice, and the higher the proportion of polymer in an ASD, the more stable it should be to crystallization (9). Indeed, as the ratio of PVP in the SD dispersions increased, a linear increase in their crystallization temperature was observed. The high $T_{g}$ of PVP should help to stabilize the ASSDs, by reducing the molecular mobility and thus crystallization tendency of the salt (14). The ASSD containing Soluplus crystallized at a slightly lower temperature than those containing 
$40 \%(\mathrm{w} / \mathrm{w})$ PVP; however, this is expected considering the significantly lower $\mathrm{T}_{\mathrm{g}}$ of this polymer.

The method of production had a small but significant effect on the crystallization temperature of the ASSDs containing CS 1:1 and 40\% (w/w) PVP, with that of the SD sample being almost $4{ }^{\circ} \mathrm{C}$ higher than BM CS 1:1/40\% PVP $(\mathrm{p}=0.001)$. In contrast, no significant difference in $\mathrm{T}_{\mathrm{g}}$ values was found between these samples $(p=0.06)$. These results are in agreement with those of other authors, who found spray dried amorphous solids to have higher physical stability and crystallization temperatures than those produced by ball milling. In each case, the ball milled samples were found to have greater molecular mobility than the equivalent spray dried samples $(29,30)$, which facilitates nucleation and crystal growth. Ball milled ASDs are also likely to be less homogeneous on a molecular level. As spray drying is carried out on a solution of a drug and polymer, the components of an ASD are molecularly mixed from the beginning of the process. This increases the likelihood that a complete glass solution will be formed. In milling on the other hand, the crystal lattice of the drug must first be disrupted before it can mix intimately with the polymer, resulting in a less homogeneous mixture.(31). A small level of inhomogeneity may have also contributed to the lower crystallization temperatures of the ball milled samples in this study.

Physical mixtures (PMs) consisting of the amorphous CS 1:1 and CS 2:1 salts and appropriate ratios of polymers were also analyzed by DSC, and their thermograms and thermal properties are shown in Figure S4 and Table SI. Individual two-sample $t$ tests were used to compare the results obtained with the ASSDs and corresponding PMs. In each case, the ASSDs showed a statistically significantly higher $\mathrm{T}_{\mathrm{g}}$ than the corresponding PMs $(\mathrm{p}<0.05)$. A statistically significantly higher crystallization temperature was also obtained for all the ASSDs compared to the PMs, except for 
SD CS $1: 1 / 20 \%$ PVP, which was almost statistically significant $(p=0.07)$. Unlike the ASSDs, the PMs did not offer an increase in $T_{g}$ relative to the pure amorphous salts, and only the PM containing CS 2:1 and 40\% (w/w) PVP demonstrated a statistically significant increase in crystallization temperature. These results indicate that simply mixing the amorphous salts with polymer offers negligible benefits in terms of thermal stability. Formulation as an ASSD on the other hand significantly increases the $T_{\mathrm{g}}$ and crystallization temperature of CS 1:1 and CS 2:1, as it allows more intimate mixing of the components. The ASSDs would therefore be expected to have higher physical stability during storage than the corresponding amorphous salts.

The water content and thermal degradation of the ASSDs was investigated using TGA (Figure S5). Between 25 and $120^{\circ} \mathrm{C}$, all of the samples underwent mass loss due to water evaporation. The greatest water loss was obtained with BM CS 2:1/40\% PVP and BM CS 1:1/40\% PVP, equal to 4.5 and $4.4 \%$, respectively. As the proportion of PVP increased in the SD samples, so did the degree of water loss, due to the high hygroscopicity of this polymer. A smaller mass loss of $2.1 \%$ occurred between $25-120^{\circ} \mathrm{C}$ with the ASSD containing Soluplus, suggesting that this polymer is less hygroscopic than PVP. Although they did not contain any polymer, the amorphous CS 1:1 and CS 2:1 salts were found to have a water content of 4.25 and $4.1 \%$, respectively. In addition to water loss, TGA analysis also showed that all of the samples undergo significant thermal degradation above $\sim 200^{\circ} \mathrm{C}$. Similar levels of degradation were seen with binary polymeric CIP ASDs (12), and the pure drug is also known to decompose upon melting (2). The thermograms of each of the amorphous samples contained broad endotherms above 180 ${ }^{\circ} \mathrm{C}$ due to melting accompanied by decomposition (Figure 3 ). 


\section{Solid-State Stability Study}

The irregular arrangement of molecules in amorphous solids enables the absorption of large quantities of water, which was shown to be the case with all of the ASSDs during DVS analysis

(Figure 4). SD CS 1:1/60\% PVP absorbed the highest amount of water (37.8\%), followed by BM CS $2: 1 / 40 \%$ PVP (29.1\%). The smallest change in mass was obtained with SD 1:1/20\% PVP (15.4\%) and BM CS 1:1/40\% Soluplus (15.9\%). SD and BM CS 1:1/40\% PVP had similar mass changes of 28.0 and $26.1 \%(\mathrm{w} / \mathrm{w})$ respectively; therefore the method of production did not have a major effect on the water uptake behavior of these samples. In comparison to the ASSDs, the mass of the amorphous CS 1:1 and CS 2:1 salts increased by approximately $10 \%$ during DVS analysis (3). Therefore, the significantly larger water uptake of the ASSDs can be attributed to the presence of hygroscopic polymer. A large degree of water absorption is expected in samples containing a molar excess of PVP monomer (8), which was the case in all of the ASSDs studied here.

DVS analysis of the pure amorphous CS 1:1 and CS 2:1 salts resulted in the crystallization of CS 1:1 trihydrate and CS 2:1 tetrahydrate, respectively, at 40-50\% RH. The latter salt then converted to the respective anhydrate during the dehydration cycle (3). The change in mass vs. time plots of the ASSDs also showed a decrease in mass during the sorption stage of the DVS study at 40-50\% RH (data not shown), which may be due to their crystallization. Therefore, the presence of polymer did not seem to improve the physical stability of the amorphous salts in high humidity conditions. PXRD analysis of the samples following a full DVS cycle (0-90-0\% RH) revealed that all the ASSDs containing CIP and succinic acid in a 1:1 molar ratio crystallized as anhydrous CS 1:1, while BM 2:1/40\% PVP formed anhydrous crystalline CS 2:1 (Figure S6). The PXRD pattern obtained with BM CS 1:1/40\% Soluplus contained an additional peak at 
approximately $9.42 \theta$ degrees, which corresponds to CS 1:1 trihydrate (3). This may be due to incomplete dehydration of CS 1:1 trihydrate during the desorption cycle. The isotherm of this ASSD also differs from those containing PVP as it shows a larger degree of hysteresis. The smaller amount of hysteresis seen with the PVP-containing ASSDs may be due to the more rapid conversion of these samples to the crystalline CS 1:1 trihydrate and anhydrate salts.

Long-term stability studies were carried out on the ASSDs at room temperature $\left(22-25^{\circ} \mathrm{C}\right)$ under dry conditions. All of the ASSDs containing PVP remained X-ray amorphous for at least 12 months, while a small peak appeared at 25.0 $2 \theta$ degrees in the PXRD pattern BM CS 1:1/40\% Soluplus after twelve months, corresponding to the most prominent peak of the crystalline anhydrous CS 1:1 salt. This ASSD therefore appears to be somewhat less stable than those containing PVP, which could be expected given its correspondingly lower $\mathrm{T}_{\mathrm{g}}$. In contrast, a small peak appeared in the PXRD pattern of amorphous CS 1:1 after only one month, and after two months both amorphous salts were partially crystalline, with peaks matching those of the corresponding anhydrous CIP succinate salts (3). These peaks then grew in intensity over time due to increasing crystalline content (Figure S7).

The presence of PVP and Soluplus in the ASSDs prevented the crystallization of CS 1:1 and CS 2:1 during long-term storage, allowing them to remain amorphous for an extended period of time. Similarly, as described in the previous section, the crystallization temperatures of all of the ASSDs were significantly higher than the polymer-free salts in DSC studies. Polymers with high glass transition temperatures such as PVP are often used to stabilize ASDs, as they will help to reduce the molecular mobility and crystallization tendency of the drug (14). However, as the $T_{g}$ of Soluplus is relatively low, this is clearly not the only explanation for the improved stability of the ASSD containing this polymer. The free energy of an amorphous formulation may be 
decreased by the presence of polymers, as their high molecular weight and flexibility will increase the configurational entropy of the system, and thus reduce the driving force for crystallization (19). In addition, polymers can provide a physical barrier to crystallization by hindering the movement of drug molecules and blocking their access to crystal growth sites (9). For instance, ASDs containing nimesulide and PVP were shown to greatly increase the resistance of the amorphous drug to crystallization, despite having lower than predicted $\mathrm{T}_{\mathrm{g}}$ 's and lacking specific interactions between the components. The improved stability of the ASDs was attributed to the steric hindrance and antiplasticization effect of the polymer. This resulted in a reduction in the molecular mobility of the drug, as shown by broadband dielectric spectroscopy (14). A combination of these factors most likely resulted in the improved stability of these ASSDs.

\section{Solubility Studies}

Due to the generation of a viscous gel when BM CS 1:1/40\% Soluplus was added to the media, it was not possible to accurately carry out solubility tests on this sample. In contrast, the ASSDs containing PVP demonstrated superior dispersion and wettability behavior, and full solubility tests were successfully carried out on all of these samples.

CIP is poorly soluble in water, reaching a concentration of only $0.09 \mathrm{mg} / \mathrm{ml}$ after two hours. As can be seen in Figure 5a, a substantial improvement in solubility was obtained with CS 1:1 and the ASSDs containing this salt. An average maximum concentration of $30-34 \mathrm{mg} / \mathrm{ml}$ was achieved for all of these samples, however the differences between them were not statistically significant, as shown by ANOVA $(\mathrm{p}=0.27)$. Similarly, Patel et al found that the solubility of tenoxicam doubled when formulated as an amorphous 1:2 salt with arginine, however the 
formation of an ASSD with PVP did not provide any additional improvement (15). With each of the ASSDs, the concentration of CIP increased sharply within the first $60 \mathrm{sec}$ of the study and did not fall substantially over the remainder of the experiment, although there was some fluctuation. CS 2:1 offered less of a solubility advantage in water than the 1:1 salt, with a maximum CIP concentration of $21.2 \mathrm{mg} / \mathrm{ml}$. Therefore, a drug-acid ratio of 1:1 enables more of the drug to enter solution in water. This may be due to a greater lowering of the $\mathrm{pH}$ due to the higher proportion of succinic acid. Surprisingly, unlike CS 1:1, the formulation of CS 2:1 as an ASSD with PVP decreased its aqueous solubility significantly to $2.1 \mathrm{mg} / \mathrm{ml}$. The aqueous solubility of CS 1:1, CS 2:1 and all of the ASSDs is significantly higher than that of binary CIP ASDs containing Eudragit L100, HPMCAS-LG and HPMCAS-MG, which displayed a maximum solubility of $0.64,1.75$ and $1.59 \mathrm{mg} / \mathrm{ml}$, respectively, in water (12). This is most likely due to the presence of succinic acid in the former samples, which is more acidic and soluble than these polymers.

Similar profiles were obtained for CIP and BM CS 2:1/40\% PVP in FaSSIF (Figure 5b). Both samples reached a peak concentration of 0.94 and $1.48 \mathrm{mg} / \mathrm{ml}$, respectively, after $30 \mathrm{sec}$. These levels quickly fell and then remained fairly constant for the remainder of the study. As in water, a significantly higher concentration was obtained with CS 1:1 and the other ASSDs in FaSSIF. After $60 \mathrm{sec}$ concentrations in excess of $39 \mathrm{mg} / \mathrm{ml}$ were obtained with all of these samples, which remained at this level for the remainder of the study. Again, the differences in the maximum concentration of these samples was not statistically significant, as shown by ANOVA $(\mathrm{p}=0.93)$

In FaSSGF CIP was more soluble, reaching a maximum concentration of $12.1 \mathrm{mg} / \mathrm{ml}$. CIP has high solubility at $\mathrm{pH}<5$, as it has a positive overall charge. On the other hand, around $\mathrm{pH} 7$ it 
will have minimal solubility due to its net neutral charge. In contrast to water and FaSSIF, in FaSSGF BM CS 2:1/40\% PVP had a comparable solubility to the other ASSDs. Similarly, the CS 2:1 amorphous salt demonstrated superior solubility in this medium, achieving a concentration of $54.5 \mathrm{mg} / \mathrm{ml}$ at the end of the study, whereas a maximum concentration of $38.9-$ $43.9 \mathrm{mg} / \mathrm{ml}$ was obtained with all of the other ASSDs (Figure 5c). ANOVA with Tukey's multiple comparison test revealed that the maximum solubility of SD CS 1:1/60\% PVP was significantly higher than that of BM CS 1:1/40\% PVP in FaSSGF, however none of the other ASSDs differed significantly. Therefore, it can be concluded that the processing method (dry ball milling vs. spray drying) did not affect the solubility of CS 1:1/40\% PVP. Similarly, the proportion (w/w) of PVP in the ASSDs prepared by spray drying did not have a significant effect on their solubility.

The $\mathrm{pH}$ of the solutions at the end of the solubility studies was measured and is listed in Table SII. As expected, very similar values were obtained with CS 1:1 and the ASSDs containing this salt. In water and FaSSIF the pH decreased to $4.6 \pm 0.1$ and $4.7 \pm 0.1$, respectively, with these samples, and in FaSSGF it increased to 4.1 \pm 0.1 . CS 2:1 gave slightly higher values of 4.7-4.9 in the three media, while the $\mathrm{pH}$ was higher again with BM CS 2:1/40\% PVP (final $\mathrm{pH} 5.4,6.0$ and 4.9 in water, FaSSIF and FaSSGF, respectively) due to the lower quantity of salt entering solution with these samples.

PXRD analysis of the excess powder left at the end of the experiments revealed that all of the amorphous solids crystallized (Figure S8). The same crystal form was obtained for all of the samples containing CS 1:1 in the three different media, which was identified as CS 1:1 trihydrate (3). In contrast, CS 2:1 and BM CS 2:1/40\% PVP did not crystallize to the corresponding salt, but instead formed CIP hydrate. In FaSSIF the PXRD patterns of the precipitates matched that 
obtained with pure CIP in water, which was found to contain 3.1 moles of water per mole of CIP (12), while in water the CIP 3.7 hydrate (32) was obtained. In FaSSGF, CS 2:1 crystallized to a mixture of the 3.1 and 3.7 hydrates. Unlike the other samples, the precipitate recovered from solubility studies with BM CS $2: 1 / 40 \%$ PVP in this medium was only slightly crystalline, with low intensity peaks matching those of the CIP 3.7 hydrate. The significantly improved solubility observed for this sample in FaSSGF compared to the other media may therefore be partly due to a delay in crystallization. The crystallization behavior of the samples may also explain the superior solubility profiles of those containing CS 1:1 compared to CS 2:1. Crystalline CS 1:1 has been shown to have a solubility of approximately $30 \mathrm{mg} / \mathrm{ml}$ in water (3), and therefore its formation during solubility studies would still result in a large amount of CIP entering solution. CIP hydrate on the other hand is significantly less soluble than CS 1:1 trihydrate (33), and its formation may have limited the drug concentration achieved with CS 2:1.

\section{Permeability Studies}

The results of the PAMPA study on CS 1:1, CS 2:1 and the ASSDs containing PVP are shown in Table II. An effective permeability $\left(\mathrm{P}_{\mathrm{e}}\right)$ of less than $1 \times 10^{-6} \mathrm{~cm} / \mathrm{s}$ is generally considered as low (34). Therefore, all of the samples tested here demonstrated low effective permeability, and would be expected to be poorly absorbed in vivo. While unionized CIP can enter and diffuse across cell membranes relatively easily, this is not true of the zwitterion, which is the predominant form of the drug at neutral $\mathrm{pH}$. This explains why the permeability of the drug is so low. Although the differences in $\mathrm{P}_{\mathrm{e}}$ between the amorphous samples were not significant, they all had a significantly lower permeability than crystalline CIP, as shown by ANOVA and Tukey's 
multiple comparison test $(\mathrm{p}<0.0005)$. Similarly, crystalline ciprofloxacin hydrochloride salt was also found to be significantly less permeable than pure CIP (12). This may be due to the fact that the proportion of CIP bearing a net positive charge is increased by these salts, making it more hydrophilic, and less likely to diffuse across the lipid membrane. Such a trade-off between solubility and permeability has been reported for other solubility enhancing formulations, such as cyclodextrins and surfactants (35). In contrast, in a previous study examining binary polymeric CIP ASDs, no decrease in the permeability of the drug was seen with samples containing Eudragit L100, HPMCAS-LG and HPMCAS-MG, as these excipients are unlikely to have a significant effect on the ionization state of the drug in solution (12).

Table II. PAMPA Permeability Values of CIP

\begin{tabular}{|l|l|}
\hline Sample & $\mathbf{P}^{\mathbf{a}} \mathbf{x} \mathbf{1 0}^{\mathbf{6}}(\mathbf{c m} / \mathbf{s})$ \\
\hline CIP & $0.56 \pm 0.06$ \\
\hline CS 1:1 & $0.13 \pm 0.02$ \\
\hline CS 2:1 & $0.11 \pm 0.01$ \\
\hline BM CS 1:1/40\% PVP & $0.12 \pm 0.01$ \\
\hline BM CS 2:1/40\% PVP & $0.12 \pm 0.02$ \\
\hline SD CS 1:1/20\% PVP & $0.12 \pm 0.03$ \\
\hline SD CS 1:1/40\% PVP & $0.12 \pm 0.02$ \\
\hline SD CS 1:1/60\% PVP & $0.12 \pm 0.00$ \\
\hline
\end{tabular}

${ }^{a} \mathrm{P}_{\mathrm{e}}$ : effective permeability. The average of three measurements is shown, \pm the standard deviation.

As PAMPA only provides an estimate of passive transcellular transport, it is possible that the in vivo absorption of these formulations was underestimated by this study. Although there is some evidence that CIP is a substrate for active transporters and efflux proteins in the intestine, it is believed to be largely absorbed passively, which includes the transmembrane and paracellular 
pathways (36). Drugs can be transported via the paracellular route in the zwitterionic and cationic form in vivo, and it has been estimated that $18 \%$ of CIP transport occurs in this manner (37). Therefore, the in vivo permeability of CIP from these samples is likely to be higher than that obtained in this PAMPA study, as at least a portion of the ionized drug would be absorbed by passing through the aqueous channels in between intestinal cells.

\section{Comparison of Ciprofloxacin Amorphous Salts, ASDs and ASSDs}

This section outlines the main differences between the behavior of the amorphous salts and ASSDs produced in this study, as well as the drug/polymer ASDs produced previously (12). Similar to the CIP/succinic acid salts, these ASDs contained acidic polymers at a concentration of $40-60 \%(\mathrm{w} / \mathrm{w})$, which formed ionic interactions with the protonated piperazine amino group of CIP.

When comparing the physical stability of all of these amorphous samples, the binary polymeric ASDs are superior. While the CS 1:1 and 2:1 salts and ASSDs all crystallized during DSC and DVS analysis, the binary ASDs remained X-ray amorphous (12). Although the presence of 20$60 \%(\mathrm{w} / \mathrm{w})$ polymer in the ASSDs did not prevent the crystallization of CS 1:1 and CS 2:1 during these processes, it did increase their $\mathrm{T}_{\mathrm{g}}$ 's and crystallization temperatures, and these properties were positively correlated with polymer concentration. However, only the ASSD containing $60 \%(\mathrm{w} / \mathrm{w}) \mathrm{PVP}$ had a $\mathrm{T}_{\mathrm{g}}$ above $100{ }^{\circ} \mathrm{C}$, whereas this was the case with all of the binary polymeric CIP ASDs. The highest $\mathrm{T}_{\mathrm{g}}$ was obtained with $\mathrm{CIP} /$ Eudragit L100, at $154^{\circ} \mathrm{C}$ 
The addition of polymer also had a positive effect on the long-term stability of the CS 1:1 and 2:1 salts. All of the ASSDs remained X-ray amorphous when stored for at least 10 months under dry conditions at RT, whereas the polymer-free amorphous salts crystallized after only 1-2 months. As discussed above, polymers can delay or prevent the crystallization of an amorphous drug in a mixture by reducing the molecular mobility of the system and providing steric hindrance. The greater stability of the binary polymeric ASDs may be due to the fact that CIP forms ionic interactions directly with the polymers in these formulations. These polymers are amorphous themselves, with high $\mathrm{T}_{\mathrm{g}}$ 's and molecular weights. In contrast, in the ASSDs the drug interacts ionically with succinic acid, which is a poor glass-forming, low molecular weight, crystalline molecule with a low $\mathrm{T}_{\mathrm{g}}$, whereas no evidence of specific interactions between PVP or Soluplus and the salts could be detected.

Regarding solubility, all of the amorphous samples containing succinic acid were significantly more soluble than the binary polymeric ASDs. This can be attributed to the $\mathrm{pH}$ lowering effect of succinic acid, which induces the ionization of CIP in solution, and thus increases its solubility. Unfortunately, the solubility advantage brought about by the ionization of CIP was offset by a corresponding decrease in permeability. In contrast, the acidic polymers present in the binary ASDs had a negligible effect on $\mathrm{pH}$, resulting in much more modest increases in the solubility of CIP. In addition, unlike the samples containing succinic acid, these formulations either had no effect on the permeability of CIP, or slightly increased it (12).

Relative to the amorphous CS 1:1 and 2:1 salts, the ASSDs offered insignificant benefit in terms of solubility or permeability, however, as mentioned above, they did improve the stability of the salts. Similarly, while higher concentrations of polymer resulted in greater thermal stability, no significant differences in solubility or permeability were seen with the samples containing 
different proportions of polymer. Of the three solid forms of CIP discussed here, i.e. amorphous salts, ASSDs and ASDs, the binary polymeric ASDs are perhaps the most promising due to their superior stability and solubility-permeability balance. However, further studies would be required in order to determine whether this translates into better oral bioavailability.

\section{Conclusions}

Amorphous solid dispersions containing ciprofloxacin succinate salts dispersed in PVP or Soluplus were successfully produced via ball milling and spray drying. Although no clear evidence of specific interactions between the salts and polymers were found via FTIR analysis, DSC and IGC indicated that the salts and polymers form a miscible mixture in each case. All of the ASSDs were superior to the corresponding salts in terms of thermal stability, with higher $\mathrm{Tg}_{\mathrm{g}}$ 's and crystallization temperatures, and these were positively correlated with the weight ratio of PVP. In addition, the ASSDs remained fully X-ray amorphous for at least 10 months during long-term stability studies, whereas the amorphous salts began to crystallize after 1-2 months. However, all of the ASSDs took up a large amount of water during DVS studies due to their polymer content, and also underwent crystallization. Therefore, in high humidity environments the ASSDs appear to have a similar stability to the pure amorphous salts.

All of the ASSDs containing CS 1:1 were over 300 times more soluble than pure CIP in water and FaSSIF, however no significant improvement was seen compared to the pure amorphous salt. No significant difference in solubility was seen between the BM and SD samples, or between the SD ASSDs containing varying proportions of PVP. CS 2:1 and the ASSD containing this salt offered less of a solubility advantage, although they were still superior to 
crystalline CIP in all media. No decrease in the effective permeability of CIP was seen with the ASSDs containing PVP compared to amorphous CS 1:1 and CS 2:1. However, all samples were significantly less permeable than pure crystalline CIP.

In conclusion, the formulation of CS 1:1 and CS 2:1 amorphous salts as ASSDs with PVP or Soluplus increased their thermal and long-term stability, but did not significantly improve their stability in humid conditions, solubility or permeability. Although the amorphous salts and ASSDs offered a significant advantage over pure crystalline CIP in terms of solubility, this was offset by a decrease in permeability.

\section{Acknowledgments}

Funding for this research was provided by the Science Foundation Ireland under Grant No.

12/RC/2275 (Synthesis and Solid State Pharmaceutical Centre).The authors wish to acknowledge Eibhlin Fitzpatrick for her participation in solubility studies, and Kieran Gallagher for help with IGC measurements.

\section{References}

1. Kawabata Y, Wada K, Nakatani M, Yamada S, Onoue S. Formulation design for poorly water-soluble drugs based on biopharmaceutics classification system: basic approaches and practical applications. Int J Pharm. 2011;420(1):1-10.

2. Mesallati H, Mugheirbi NA, Tajber L. Two faces of ciprofloxacin: investigation of proton 
transfer in solid state transformations. Cryst Growth Des. 2016;16(11):6574-85.

3. Paluch KJ, McCabe T, Müller-Bunz H, Corrigan OI, Healy AM, Tajber L. Formation and physicochemical properties of crystalline and amorphous salts with different stoichiometries formed between ciprofloxacin and succinic acid. Mol Pharm. $2013 ; 10(10): 3640-54$.

4. Zhang C-L, Zhao F, Wang Y. Thermodynamics of the solubility of ciprofloxacin in methanol, ethanol, 1-propanol, acetone, and chloroform from 293.15 to 333.15K. J Mol Liq. 2010;156(2-3):191-3.

5. Zaki NM, Artursson P, Bergström CAS. A modified physiological BCS for prediction of intestinal absorption in drug discovery. Mol Pharm. 2010;7(5):1478-87.

6. Yu L. Amorphous pharmaceutical solids: preparation, characterization and stabilization. Adv Drug Deliv Rev. 2001;48(1):27-42.

7. Brough $\mathrm{C}$, Williams RO. Amorphous solid dispersions and nano-crystal technologies for poorly water-soluble drug delivery. Int J Pharm. 2013;453(1):157-66.

8. Crowley KJ, Zografi G. Water vapor absorption into amorphous hydrophobic drug/poly(vinylpyrrolidone) dispersions. J Pharm Sci. 2002;91(10):2150-65.

9. Yang J, Grey K, Doney J. An improved kinetics approach to describe the physical stability of amorphous solid dispersions. Int J Pharm. 2010;384(1-2):24-31.

10. Cheong H-A, Choi H-K. Enhanced percutaneous absorption of piroxicam via salt formation with ethanolamines. Pharm Res. 2002;19(9):1375-80. 
11. Zhang G, Zhang L, Yang D, Zhang N, He L, Du G, et al. Salt screening and characterization of ciprofloxacin. Acta Crystallogr Sect B Struct Sci Cryst Eng Mater. 2016;72(1):20-8.

12. Mesallati H, Umerska A, Paluch K, Tajber L. Amorphous polymeric drug salts as ionic solid dispersion forms of ciprofloxacin. Mol Pharm. 2017;14(7):2209-23.

13. Djuris J, Nikolakakis I, Ibric S, Djuric Z, Kachrimanis K. Preparation of carbamazepineSoluplus ${ }^{\circledR}$ solid dispersions by hot-melt extrusion, and prediction of drug-polymer miscibility by thermodynamic model fitting. Eur J Pharm Biopharm. 2013;84(1):228-37.

14. Knapik J, Wojnarowska Z, Grzybowska K, Tajber L, Mesallati H, Paluch KJ, et al. Molecular dynamics and physical stability of amorphous nimesulide drug and its binary drug-polymer systems. Mol Pharm. 2016;13(6):1937-46.

15. Patel JR, Carlton RA, Yuniatine F, Needham TE, Wu L, Vogt FG. Preparation and structural characterization of amorphous spray-dried dispersions of tenoxicam with enhanced dissolution. J Pharm Sci. 2012;101(2):641-63.

16. Kitak T, Dumičić A, Planinšek O, Šibanc R, Srčič S. Determination of solubility parameters of ibuprofen and ibuprofen lysinate. Molecules. 2015;20(12):21549-68.

17. Merck Millipore. Lipid-PAMPA with the MultiScreen ${ }^{\circledR}$ filter plates. Billerica, MA; 2004.

18. Wohnsland F, Faller B. High-throughput permeability $\mathrm{pH}$ profile and high-throughput alkane/water $\log \mathrm{P}$ with artificial membranes. J Med Chem. 2001;44(6):923-30.

19. Baghel S, Cathcart H, O’Reilly NJ. Polymeric amorphous solid dispersions: A review of amorphization, crystallization, stabilization, solid-state characterization, and aqueous solubilization of Biopharmaceutical Classification System class II drugs. J Pharm Sci. 
2016;105(9):2527-44.

20. Caron V, Hu Y, Tajber L, Erxleben A, Corrigan OI, McArdle P, et al. Amorphous solid dispersions of sulfonamide/Soluplus ${ }^{\circledR}$ and sulfonamide/PVP prepared by ball milling. AAPS PharmSciTech. 2013;14(1):464-74.

21. Dorofeev VL. The betainelike structure and infrared spectra of drugs of the fluoroquinolone group. Pharm Chem J. 2004;38(12):698-702.

22. Parojčić J, Stojković A, Tajber L, Grbić S, Paluch KJ, Djurić Z, et al. Biopharmaceutical characterization of ciprofloxacin $\mathrm{HCl}$-ferrous sulfate interaction. J Pharm Sci. 2011;100(12):5174-84.

23. Chen Y, Wang S, Wang S, Liu C, Su C, Hageman M, et al. Initial drug dissolution from amorphous solid dispersions controlled by polymer dissolution and drug-polymer interaction. Pharm Res. 2016;33(10):2445-58.

24. Shalaev EY, Gatlin LA. The impact of buffer on solid-state properties and stability of freeze-dried dosage forms. In: Jameel F, Hershenson S, editors. Formulation and process development strategies for manufacturing biopharmaceuticals. 1st ed. New Jersey: John Wiley \& Sons, Inc.; 2010. p. 508.

25. Brostow W, Chiu R, Kalogeras IM, Vassilikou-Dova A. Prediction of glass transition temperatures: binary blends and copolymers. Mater Lett. 2008;62(17-18):3152-5.

26. Knopp MM, Tajber L, Tian Y, Olesen NE, Jones DS, Kozyra A, et al. Comparative study of different methods for the prediction of drug-polymer solubility. Mol Pharm. 2015;12(9):3408-19. 
27. Greenhalgh DJ, Williams AC, Timmins P, York P. Solubility parameters as predictors of miscibility in solid dispersions. J Pharm Sci. 1999;88(11):1182-90.

28. Trasi NS, Boerrigter SXM, Byrn SR. Investigation of the milling-induced thermal behavior of crystalline and amorphous griseofulvin. Pharm Res. 2010;27(7):1377-89.

29. Karmwar P, Graeser K, Gordon KC, Strachan CJ, Rades T. Investigation of properties and recrystallisation behaviour of amorphous indomethacin samples prepared by different methods. Int J Pharm. 2011 Sep 30;417(1-2):94-100.

30. Ke P, Hasegawa S, Al-Obaidi H, Buckton G. Investigation of preparation methods on surface/bulk structural relaxation and glass fragility of amorphous solid dispersions. Int J Pharm. 2012 Jan 17;422(1-2):170-8.

31. Caron V, Tajber L, Corrigan OI, Healy AM. A comparison of spray drying and milling in the production of amorphous dispersions of sulfathiazole/polyvinylpyrrolidone and sulfadimidine/polyvinylpyrrolidone. Mol Pharm. American Chemical Society; 2011 Apr 4;8(2):532-42.

32. Mafra L, Santos SM, Siegel R, Alves I, Paz FAA, Dudenko D, et al. Packing interactions in hydrated and anhydrous forms of the antibiotic ciprofloxacin: a solid-state NMR, X-ray diffraction, and computer simulation study. J Am Chem Soc. 2012;134(1):71-4.

33. Li X, Zhi F, Hu Y. Investigation of excipient and processing on solid phase transformation and dissolution of ciprofloxacin. Int J Pharm. 2007;328(2):177-82.

34. Sugano K. Permeability of a drug. In: Biopharmaceutics modeling and simulations: theory, practice, methods, and applications. 1st ed. New Jersey: John Wiley \& Sons; 2012. p. 170. 
35. Beig A, Miller JM, Lindley D, Carr RA, Zocharski P, Agbaria R, et al. Head-to-head comparison of different solubility-enabling formulations of etoposide and their consequent solubility-permeability interplay. J Pharm Sci. 2015 May 18;104(9):2941-7.

36. Rodríguez-Ibáñez M, Sánchez-Castaño G, Montalar-Montero M, Garrigues TM, Bermejo M, Merino V. Mathematical modelling of in situ and in vitro efflux of ciprofloxacin and grepafloxacin. Int J Pharm. 2006;307(1):33-41.

37. Tam KY, Avdeef A, Tsinman O, Sun N. The permeation of amphoteric drugs through artificial membranes--an in combo absorption model based on paracellular and transmembrane permeability. J Med Chem. 2010;53(1):392-401. 


\title{
Polymer/Amorphous Salt Solid Dispersions of Ciprofloxacin
}

\author{
Hanah Mesallati and Lidia Tajber
}

Synthesis and Solid State Pharmaceutical Centre, School of Pharmacy and Pharmaceutical

Sciences, Trinity College Dublin, College Green, Dublin 2, Ireland. 


\section{Legend to Figures}

Figure 1. PXRD analysis of (a) CS $1: 1$ (b) CS 2:1 (c) BM CS 1:1/40\% Soluplus (d) BM CS 2:1/40\% PVP (e) BM CS 1:1/40\% PVP (f) SD CS 1:1/20\% PVP (g) SD CS 1:1/40\% PVP and (h) SD CS $1: 1 / 60 \%$ PVP.

Figure 2. FTIR spectra of CIP ASSDs. I. Containing PVP: (a) SD CS 1:1/60\% PVP (b) SD CS 1:1/40\% PVP (c) SD CS 1:1/20\% PVP (d) BM CS 2:1/40\% PVP (e) BM CS 1:1/40\% PVP (f) CS 2:1 (g) CS 1:1 (h) PVP (i) succinic acid and (j) CIP. The inset shows an enlarged region of the spectrum of CIP, containing the peak corresponding to the $\mathrm{NH}_{2}{ }^{+}$stretch of the drug. II. Containing Soluplus: (a) BM CS 1:1/40\% Soluplus (b) CS 1:1/40\% Soluplus PM (c) CS 1:1 (d) Soluplus (e) succinic acid and (f) CIP.

Figure 3. DSC thermograms of (a) CS 1:1 (b) CS 2:1 (c) BM CS 1:1/40\% PVP (d) BM CS 2:1/40\% PVP (e) BM CS 1:1/40\% Soluplus (f) SD CS 1:1/20\% PVP (g) SD CS 1:1/40\% PVP and (h) SD CS 1:1/60\% PVP. The insets show the first derivative of the thermal signal. For clarity, the arrows indicate the glass transition temperatures, now represented as peak values.

Figure 4. DVS analysis of ASSDs produced by (a) ball milling and (b) spray drying.

Figure 5. Solubility studies in (a) water (b) FaSSIF and (c) FaSSGF at $37{ }^{\circ} \mathrm{C}$. The average of at least 3 experiments are plotted, \pm the standard deviation. 
(a) (b) 1250 au
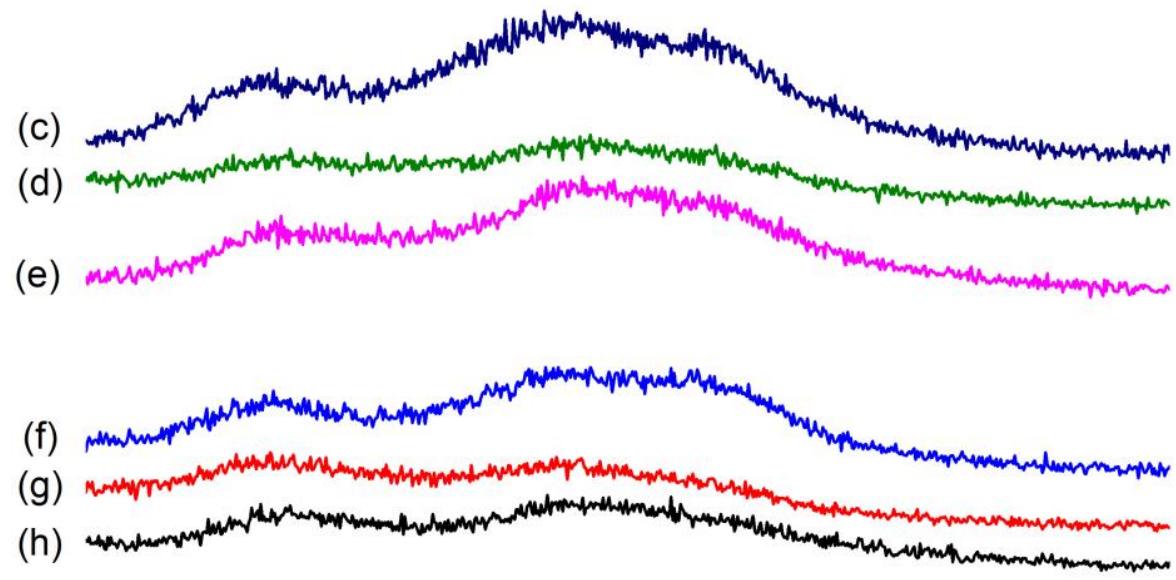

\begin{tabular}{rrrrrrrrr}
\hline 5 & 10 & 15 & 20 & 25 & 30 & 35 & 40 \\
& & 20 degrees & & &
\end{tabular}

Figure 1 
I.

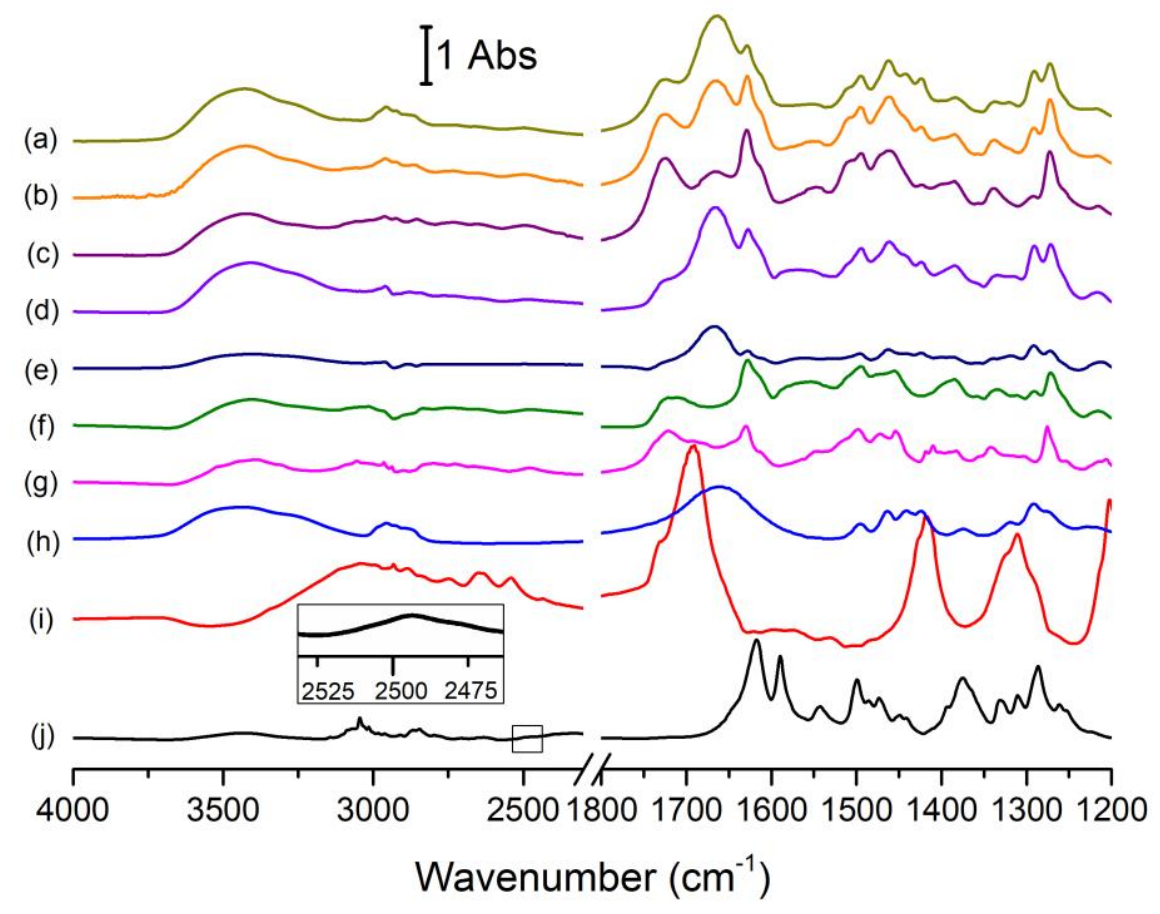

II.

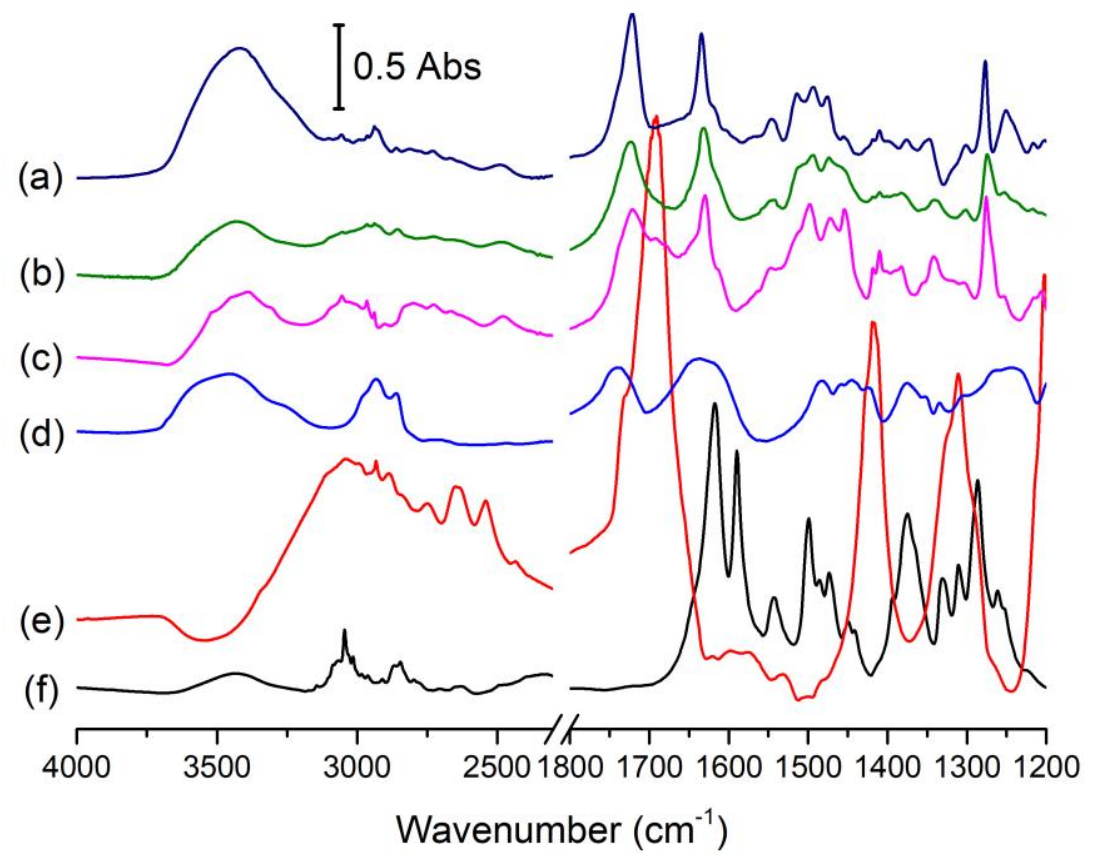

Figure 2 


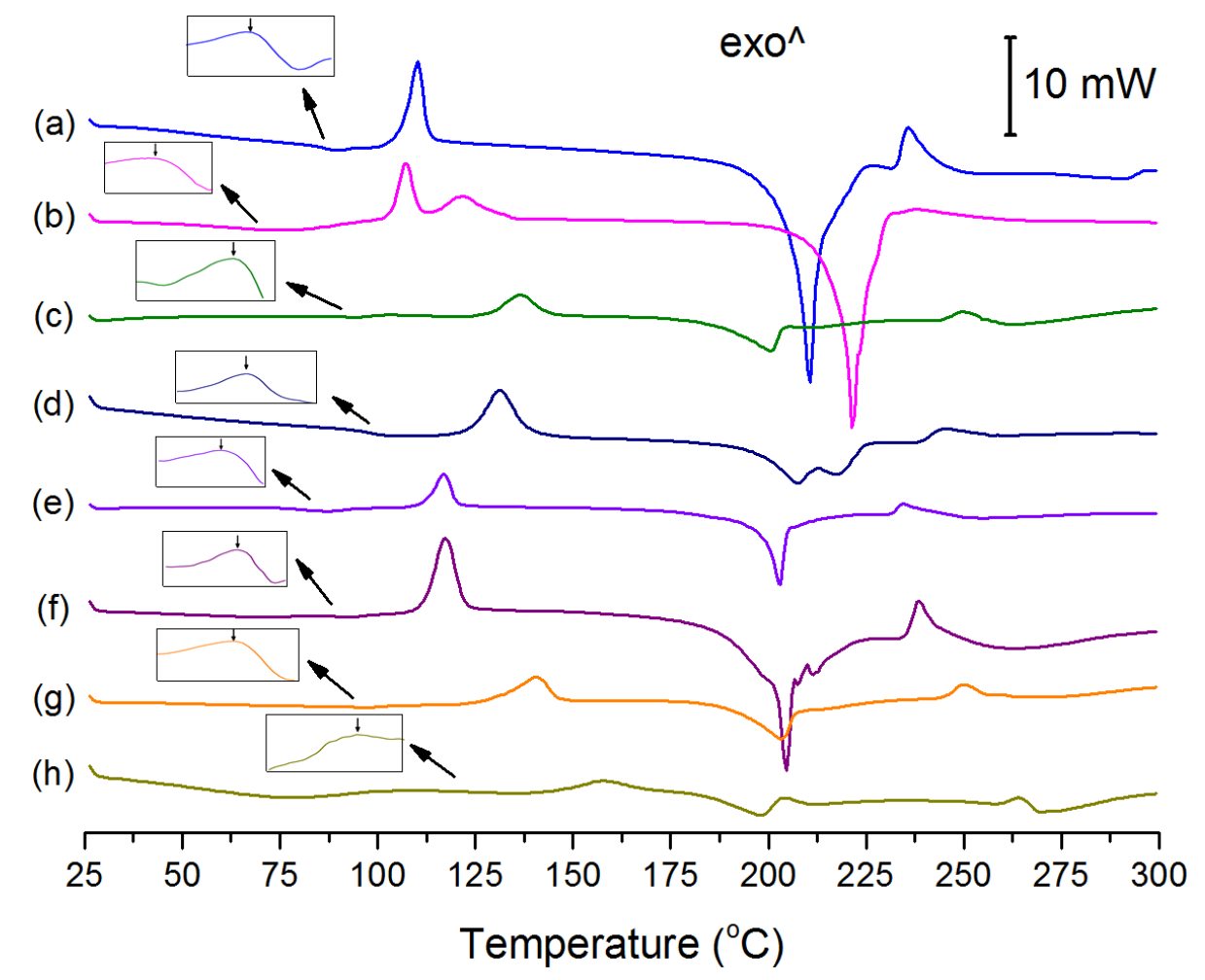

Figure 3 
(a)

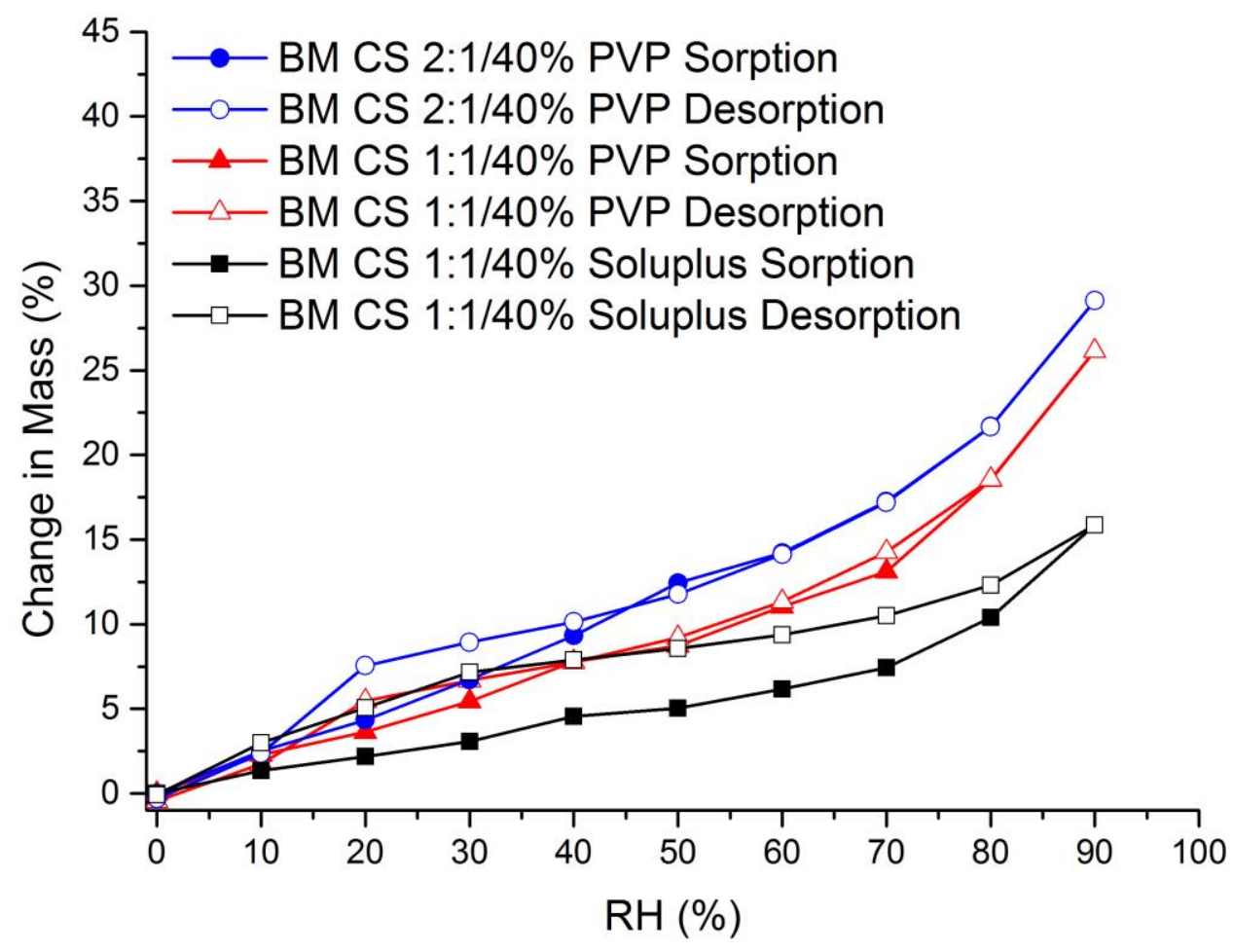

(b)

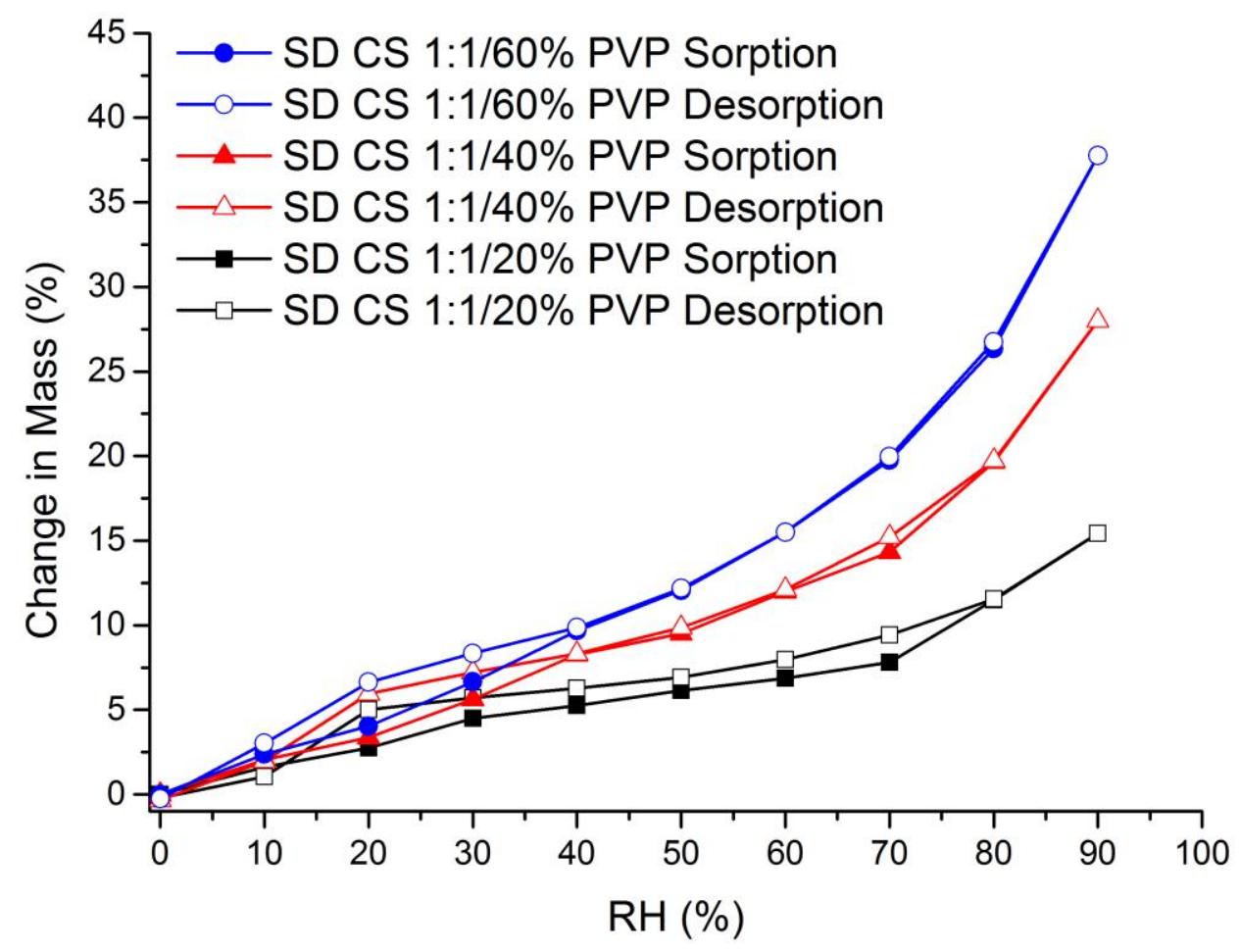


Figure 4
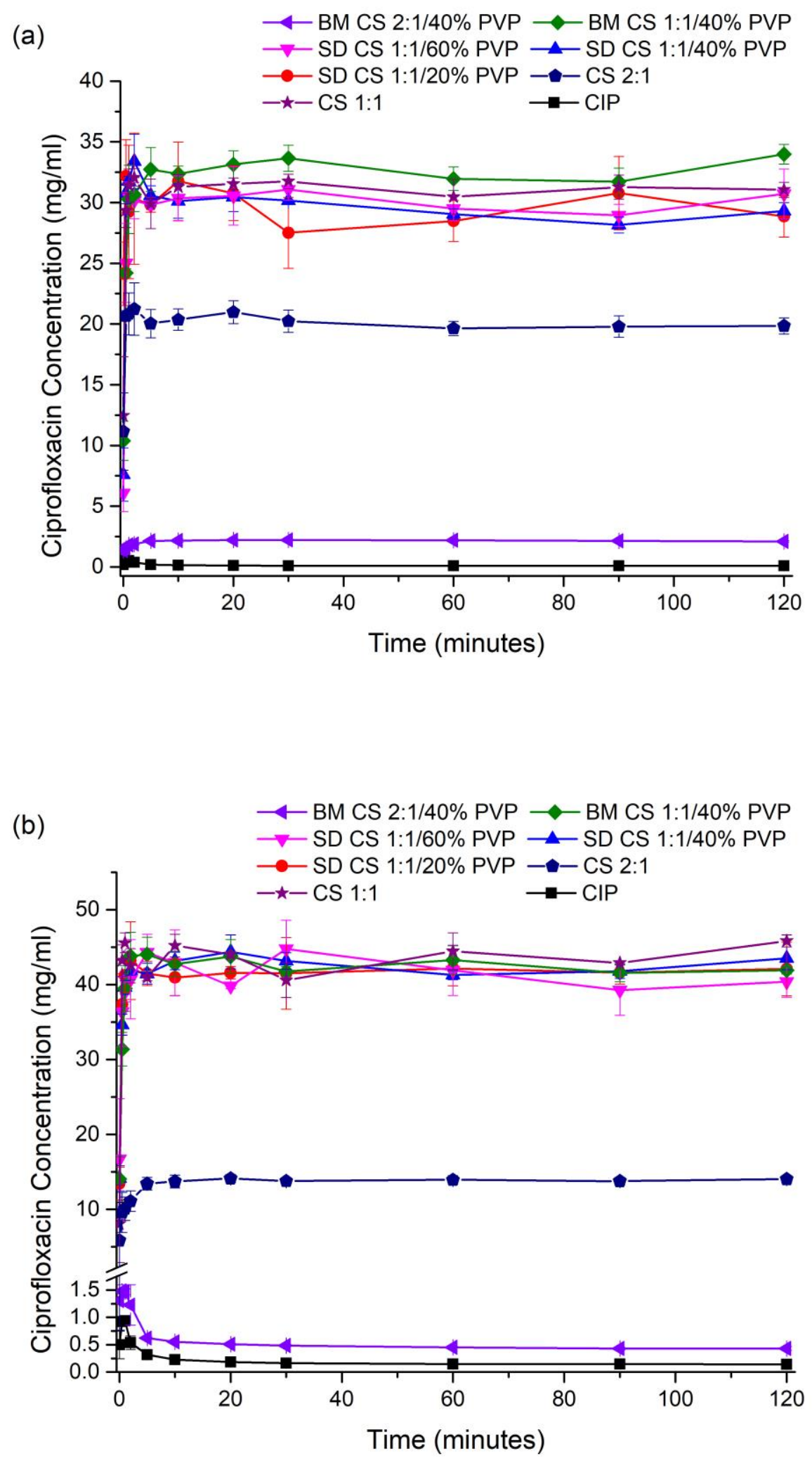
(c)

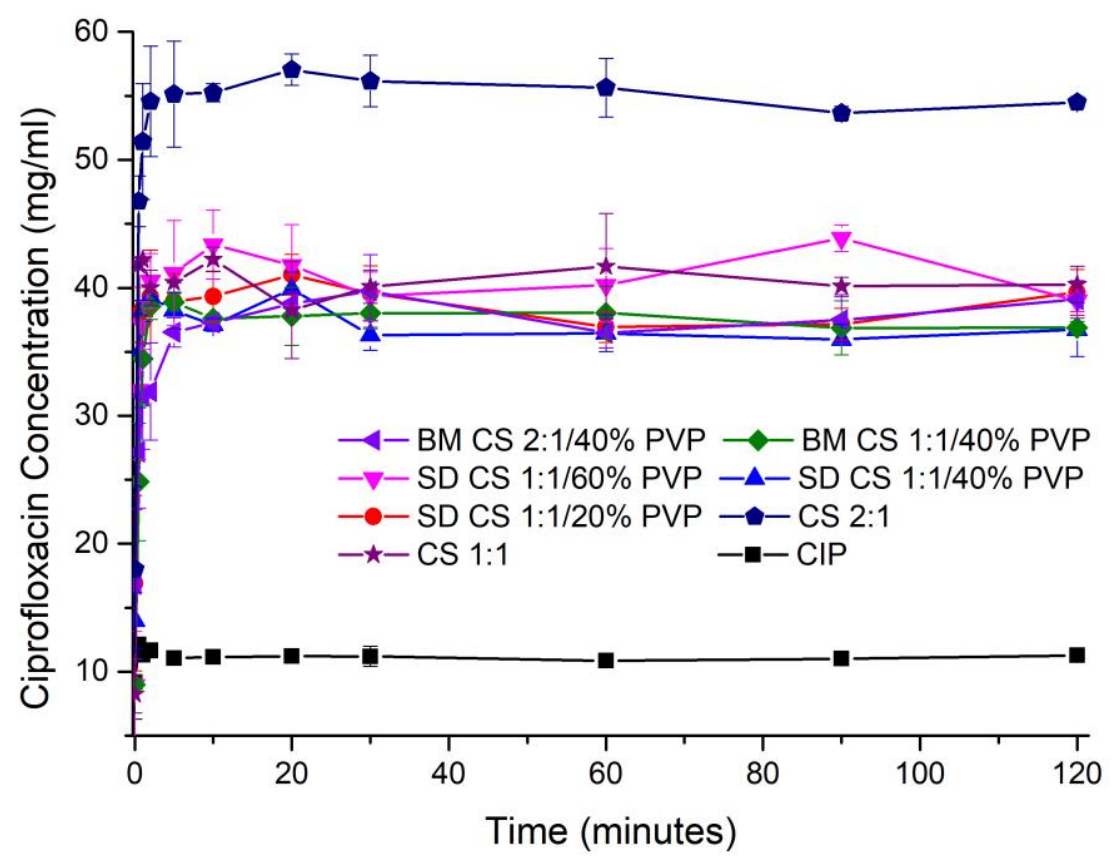

Figure 5 